DOI: 10.5216/rpp.v14i2.11443

\title{
TEMPO DE REAÇÃO E EQUILÍBRIO DE ESCOLARES COM E SEM PROFESSOR DE EDUCAÇÃO FÍSICA NAS SÉRIES INICIAIS
}

\author{
Rosenan Brum Rodrigues \\ Universidade Federal de Santa Maria, Santa Maria, Rio Grande do Sul, Brasil \\ Elisandra Postai \\ Universidade Federal de Santa Maria, Santa Maria, Rio Grande do Sul, Brasil \\ Juliana Izabel Katzer \\ Universidade Federal de Pelotas, Pelotas, Rio Grande do Sul, Brasil

\section{Luciana Erina Palma} \\ Universidade Federal de Santa Maria, Santa Maria, Rio Grande do Sul, Brasil

\section{Sara Teresinha Corazza} \\ Universidade Federal de Santa Maria, Santa Maria, Rio Grande do Sul, Brasil
}

Resumo: O objetivo do estudo foi verificar o nível de equilíbrio e o tempo de reação de escolares com e sem professor de Educação Física nas séries iniciais e identificar o cotidiano $\mathrm{e}$ as vivências motoras dos mesmos com intuito de conhecer seu comportamento motor fora do ambiente escolar. Participaram do estudo 76 escolares do $5^{\circ}$ ano. A avaliação das variáveis foi realizada por dois testes do TBO 14 e para avaliar o cotidiano e as vivências motoras dos alunos utilizou-se uma entrevista. As variáveis foram tratadas estatisticamente através do Teste $t$, com nível de significância de $5 \%$, no qual não houve diferença estatisticamente significativa. Nas entrevistas, os resultados revelaram que a maioria dos alunos que não vivenciou educação física participa de atividades físicas fora da escola $(60 \%)$, o que pode ter influenciado os resultados dos testes.

Palavras-chave: Educação Física. Equilíbrio. Tempo de Reação. Séries Iniciais.

\section{Introdução}

Movimento é o que essencialmente permite a criança desde pequena viver, pois permite exploração do meio ambiente, relacionamento com sua família, seus amigos, seu grupo, e é por meio deste que experimenta suas potencialidades e seus limites, exprime suas emoções, sentimentos e pensamentos. Ao dominar seu corpo em movimento e expressar diferentes formas de movimentos e atividades, progressivamente vai se afirmando como pessoa, obtendo maior autoconfiança, independência, autonomia e expressividade e, é com o corpo em movimento que a criança elabora todas as suas experiências vitais e organiza a sua personalidade (SOARES, 1984).

Segundo Santos, Dantas e Oliveira (2004) o desenvolvimento motor na infância caracteriza-se pela aquisição de um amplo espectro de habilidades motoras, que 
possibilita à criança o domínio do seu corpo em diferentes posturas (estáticas e dinâmicas), locomover-se pelo meio ambiente de variadas formas (andar, correr, saltar, etc.) e manipular objetos e instrumentos diversos (receber uma bola, arremessar, chutar, escrever entre outros).

Assim, a Educação Física tem um papel fundamental na educação infantil, por ter a possibilidade de proporcionar às crianças uma diversidade de experiências a partir de situações nas quais elas possam criar e descobrir movimentos novos, com o intuito de elaborar conceitos e ideias sobre o movimento e suas ações.

Para Darido e Rangel (2005), em geral nas séries iniciais do ensino fundamental e na educação infantil, as aulas de Educação Física, com algumas exceções, não são ministradas por profissionais da área, e sim desenvolvidas por meio da unidocência, ou seja, essas aulas são ministradas pelo próprio professor da classe chamado pedagogo. Porém, para Silva e Filho (2004) torna-se atribuição do professor de Educação Física direcionar o movimento para situações concretas, que conduzam o aluno à prática de atividades corporais adequadas a cada faixa etária, garantindo a construção básica de uma motricidade eficiente, voltada para uma aprendizagem segura.

Ao enfocar o aluno e sua aprendizagem ressalta-se a importância da aprendizagem motora, que segundo Schmidt e Wrisberg (2001) refere-se a uma conseqüência de processos associados com a prática ou experiência levando a uma mudança permanente na capacidade de executar respostas. Dentro do campo de estudo da aprendizagem motora, muitos focos de investigação têm sido abordados, um deles é a verificação de como as capacidades físico-motoras e as habilidades básicas se estruturam para dar consistência às habilidades específicas (MAGILL, 2000; TANI et al., 2005; SCHMIDT; WRISBERG, 2010). Percebe-se, portanto que para o desenvolvimento de habilidades específicas é importante formar a estrutura de base com enfoque nas capacidades físico-motoras. Como exemplos de capacidades físico-motoras têm-se coordenação motora, resistência, força, velocidade e flexibilidade, diferenciação cinestésica, orientação espacial, tempo de reação, equilíbrio e ritmo (SCHMIDT; WRISBERG, 2010). No presente estudo explorou-se o equilíbrio e o tempo de reação.

O equilíbrio segundo Spirduso (2005), Mochizuki e Amadio (2004), Lemos et al. (2008) e Sonza, Machado e Mocuizuki (2005) se caracteriza na possibilidade de manter a posição do corpo sobre sua base de apoio, seja essa base estacionária ou móvel, sendo que pode ser dividido em estático e dinâmico. O equilíbrio estático pode ser definido como uma qualidade física que o indivíduo possui ao permanecer em uma posição imóvel (JOHNSON; NELSON, 1986), o uso pertinente de informações internas e externas para reagir a perturbações de estabilidade e ativar os músculos para trabalhar em coordenação de modo a prevenir mudanças no equilíbrio é chamado de equilíbrio dinâmico.

O equilíbrio corporal é fundamental no relacionamento espacial do homem com o ambiente, principalmente em crianças que estão com o organismo e sentidos em formação, no qual um bom aprimoramento da manutenção do equilíbrio pode ser benéfico para as atividades da vida diária e também para as atividades futuras, como as desenvolvidas na vida adulta e até na velhice para evitar quedas e ter uma boa qualidade de vida (TAGUSHI, 2005 apud ALVES; TEIXEIRA, 2008).

O tempo de reação é definido por Magill (2000) como uma medida de resultado do desempenho que indica quanto tempo uma pessoa leva para iniciar um movimento,

Pensar a Prática, Goiânia, v. 14, n. 2, p. 1-15, maio/ago. 2011 
ou ainda, o intervalo de tempo entre um estímulo e o início de uma resposta de movimento e inclui não o movimento em si, mas somente o tempo antes do movimento começar. O tempo de reação tem funções muito importantes nos esportes e em atividades da vida diária é tido como componente fundamental na realização de muitas habilidades, considerando-se que o resultado da execução de tal habilidade se dá a partir de uma série de processamentos mentais (BINOTTO, 2007).

A Educação Física escolar além de proporcionar o desenvolvimento de habilidades básicas para crianças que se encontram na faixa etária das séries iniciais do ensino fundamental, objetiva desenvolver a postura crítica dos alunos perante as atividades da cultura corporal, no sentido da aquisição de autonomia de conhecimentos/habilidades/capacidades necessários a uma prática intencional e permanente, considerando o lúdico e os processos sócio-comunicativos no sentido do prazer, da auto-realização e da qualidade de vida (VAGO, 1999; JEBER, 1997).

Quanto à exploração de diferentes possibilidades de manifestação da cultura corporal, Betti e Zulliani (2002) defendem a importância do professor de Educação Física e este deve proporcionar aos alunos oportunidades para a realização dos jogos, esportes, atividades rítmicas/expressivas, lutas e artes marciais, ginástica e prática de atividade física, assim como, a exploração das variações destes conteúdos sempre considerando e respeitando os limites individuais do aluno.

Com base nestes pressupostos este estudo visa verificar o nível de equilíbrio e o tempo de reação de escolares com e sem professor de Educação Física nas séries iniciais e identificar o cotidiano e vivências motoras dos grupos.

\section{Método}

Grupo de estudos

Fizeram parte da pesquisa 76 escolares do $5^{\circ}$ ano do ensino fundamental de ambos os sexos, sendo 40 destes de escolas municipais em que não há 0 acompanhamento de profissionais de Educação Física nas séries iniciais e 36 escolares de escolas em que acontece o acompanhamento deste profissional no referido período escolar, situadas na cidade de Santa Maria, RS.

O critério utilizado para a escolha deste grupo se deu a partir da hipótese de que os alunos que tiveram Educação Física nas séries iniciais já vivenciaram atividades que desenvolvem as capacidades físico motora e habilidades básicas há quatro anos, portanto, teriam uma base motora desenvolvida, enquanto que o grupo que não teve Educação Física neste período está começando a desenvolver estas atividades, ou seja começando a desenvolver esta base motora. Como critérios de exclusão foram definidos a participação inferior dos alunos em 75\% das aulas, alunos que foram transferidos para as escolas há pouco tempo e ter idade superior a 14 anos e meio de idade.

O estudo foi aprovado pelo Comitê de Ética da Universidade Federal de Santa Maria (UFSM), baseado nas Diretrizes e Normas Regulamentadoras de Pesquisa envolvendo seres humanos do Conselho Nacional de Saúde e autorização dos responsáveis e alunos para participação consentida, CAEE $n^{\circ}$. 0015.0.243.000-10.

Pensar a Prática, Goiânia, v. 14, n. 2, p. 1-15, maio/ago. 2011 
$\mathrm{O}$ instrumento

Foi utilizado o Protocolo de Testes de Proeficiência Motora (TBO 14), proposto por Bruininski e Oseretsky (Bruininski, 1978), cujo objetivo é fornecer informações a respeito da motricidade de um indivíduo, a partir de seu desempenho em determinadas habilidades ou capacidades motoras, que pode ser utilizado em indivíduos que se encontram entre 4 anos e meio e 14 anos e meio de idade.

O teste é constituído por 8 subtestes que, em seu conteúdo, representam aspectos importantes da motricidade e de seu desenvolvimento no indivíduo. Para a realização desta pesquisa foram utilizados o subteste 2 (Itens 2 e 7 - Equilíbrio estático e dinâmico: em pé, com a perna preferida sobre a trave de equilíbrio e andando para a frente sobre a trave de equilíbrio) e o subteste 6 para medir o tempo de reação dos escolares ( Item 1 - Tempo de reação: medida de velocidade de reação em que deve-se segurar a régua de velocidade de resposta colocada junto a uma parede plana).

Os testes foram realizados individualmente durante as aulas de educação física dos alunos em salas de aula fechadas, limpas, iluminadas e silenciosas, contendo a presença de dois avaliadores, previamente treinados para avaliação e orientação das tarefas.

Entrevista

Foi criada uma entrevista semi-estruturada, validada a partir da Escala Lickert por três profissionais da área para que pudesse ser utilizada na pesquisa. Esta foi aplicada aos sujeitos com intuito de conhecer seu comportamento motor, sendo realizada após a submissão dos escolares aos testes.

No conteúdo da entrevista havia questionamentos referentes ao cotidiano dos alunos, onde moravam, que locais frequentavam para que pudessem se movimentar, que brincadeiras costumavam realizar, a participação dos alunos em atividades esportivas fora do contexto escolar entre outros.

Análise estatística

Primeiramente foi feita a análise descritiva (média, desvio padrão e percentil) dos dados. Para verificar a normalidade dos dados foi utilizado o Teste de Shapiro Wilk. Na verificação das diferenças foi utilizado um Teste $t$ para amostras independentes com nível de significância de 5\%. O pacote estatístico utilizado foi SPSS for Windows versão 14.0.

\section{Resultados}

O grupo de estudos final foi constituído de 76 indivíduos, sendo 40 alunos que não tiveram acompanhamento de profissional de Educação Física nas séries iniciais do ensino fundamental e 36 alunos que tiveram acompanhamento do profissional no referido período escolar. A faixa etária dos sujeitos esteve entre 8 e 14 anos, sendo a média de idade destes de 10,1 anos. 
A seguinte tabela (tabela 1) apresenta os dados referentes às variáveis Equilíbrio Estático (EE), Equilíbrio Dinâmico (ED) e Tempo de Reação (TR), para os grupos Sem Professor de Educação Física nas séries iniciais (GA) e Com Professor de Educação Física nas séries iniciais (GB), representando o Número de sujeitos da pesquisa (N), a média dos resultados dos grupos para cada variável, o Desvio Padrão (DP) encontrado e o valor do Teste t.

Tabela 1: Resultados dos testes realizados

\begin{tabular}{c|c|c|c|c|c}
\hline Variável & Grupo & $\mathbf{N}$ & Média & DP & Teste t \\
\hline \multirow{3}{*}{ E E } & GA & 40 & $5,93 \mathrm{~s}$ & 0,350 & \multirow{2}{*}{$-1,285$} \\
\cline { 2 - 5 } & GB & 36 & $6,00 \mathrm{~s}$ &, 000 & \\
\cline { 2 - 5 } & GA & 40 & $2,00 \mathrm{~s}$ & 1,198 & \multirow{3}{*}{$-0,924$} \\
\cline { 2 - 5 } & GB & 36 & $2,25 \mathrm{~s}$ & 1,156 & \multirow{3}{*}{$-0,454$} \\
\cline { 2 - 5 } T R & GA & 40 & 6,35 & 2,271 & 2,739 \\
\cline { 2 - 5 } & GB & 36 & 6,61 &
\end{tabular}

Legenda: $\mathbf{E E}=$ Equilíbrio Estático, $\mathbf{E D}=$ Equilíbrio Dinâmico, $\mathbf{T R}=$ Tempo de Reação, $\mathbf{G A}=$ Grupo A, sem professor de Educação Física, GB = Grupo B, com professor de Educação Física, N= Número de participantes, $\mathbf{D P}=$ Desvio Padrão

Analisando as médias nos testes do Grupo B pode-se verificar uma leve superioridade no desempenho ao comparar com as médias do Grupo A, o que permite afirmar que mesmo sendo pequena a diferença pode-se notar que as aulas de Educação Física para o Grupo B trouxeram um benefício e permitiram um melhor desempenho nos testes em relação ao Grupo A.

No entanto a aprtir dos resultados obtidos pelo Teste t pode-se verificar que não houve diferença estatisticamente significativa entre os grupos, ou seja, não há uma diferença entre as variáveis analisadas para esse grupo de escolares. Com este resultado constata-se que na Educação Física vivenciada pelos alunos destas instituições não estão sendo desenvolvidas atividades que explorem especificamente o equilíbrio e o tempo de reação.

Quanto aos resultados obtidos na entrevista realizada junto ao grupo de estudos apresenta-se a seguir por meio de gráficos em percentis os dados mais importantes.

O gráfico 1 apresenta os resultados referentes ao questionamento sobre moradia em casas dos componentes de GA e GB.

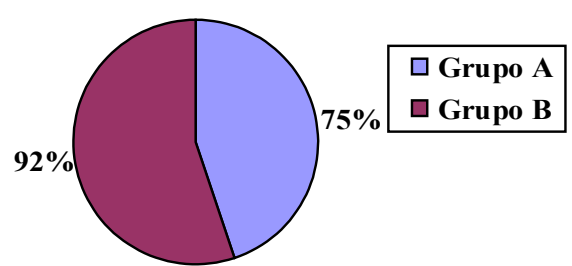

Gráfico 1 - GA - Sem professor de Ed. Física; GB - Com professor de Ed. Física

O gráfico 2 apresenta os resultados referentes à alunos que têm espaço para desenvolver atividades físicas em sua moradia dos componentes de GA e GB.

Pensar a Prática, Goiânia, v. 14, n. 2, p. 1-15, maio/ago. 2011 


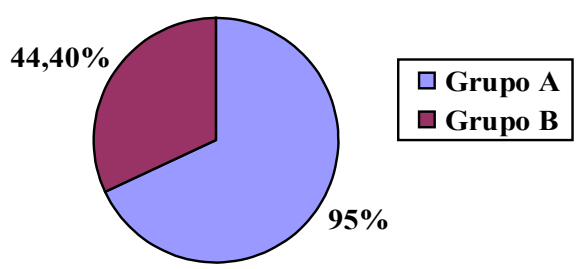

Gráfico 2 - GA - Sem professor de Ed. Física; GB - Com professor de Ed. Física

O Gráfico 3 apresenta os resultados referentes à brincadeiras que os alunos de GA costumam realizar.

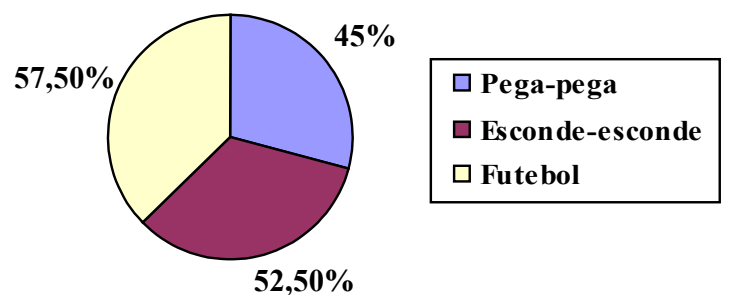

Gráfico 3 - Brincadeiras que GA - Sem professor de Educação Física, costumam realizar

O Gráfico 4 apresenta os resultados referentes à brincadeiras que os alunos de GB costumam realizar.

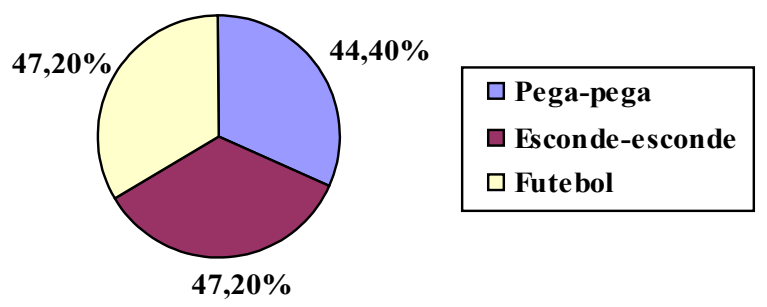

Gráfico 4 - Brincadeiras que GB - Com professor de Educação Física, costumam realizar

O Gráfico 5 apresenta os resultados referentes à Participação em atividades físicas (escolinhas) fora das aulas de educação física dos componentes de GA e GB.

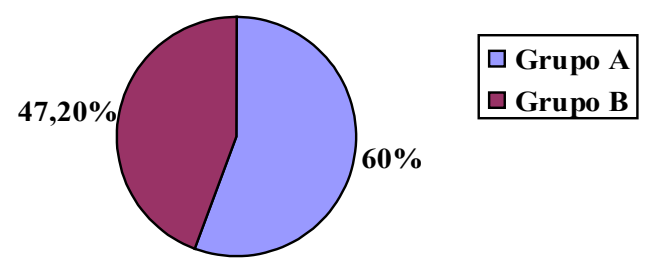

Gráfico 5 - GA - Sem professor de Ed. Física; GB - Com professor de Ed. Física

O Gráfico 6 apresenta os resultados referentes à atividades físicas (escolinhas) fora das aulas de educação física escolar que os alunos de GA costumam participar.

Pensar a Prática, Goiânia, v. 14, n. 2, p. 1-15, maio/ago. 2011 


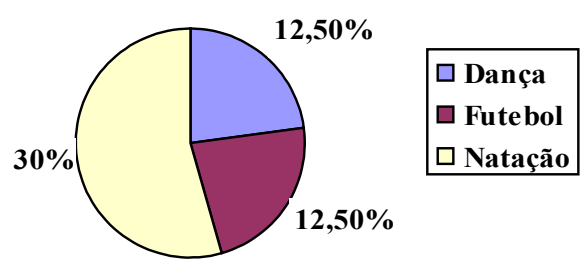

Gráfico 6 - Atividades físicas (escolinhas) que GA - Sem professor de Educação Física, participam

O Gráfico 7 apresenta os resultados referentes à atividades físicas (escolinhas) fora das aulas de educação física escolar que os alunos de GB costumam participar.

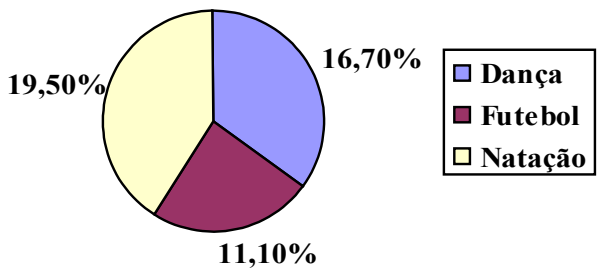

Gráfico 7 - Atividades físicas (escolinhas) que GB - Com professor de Educação Física, participam

A partir dos resultados obtidos na entrevista pode-se notar que a maioria dos alunos que não vivenciou aulas de educação física nas séries iniciais participa de escolinhas além das aulas de educação física escolar, o que pode ter influenciado nos dados obtidos nos testes motores. Também cabe salientar que os alunos deste mesmo grupo têm mais acesso a espaços para realização de brincadeiras e atividades físicas, talvez estes dois fatores podem ter sido de fundamental importância para influenciar nos resultados obtidos junto aos testes motores.

\section{Discussão}

Com base nos resultados, não foram encontradas diferenças significativas estatisticamente, após a comparação dos dados apresentados por alunos que têm acompanhamento de um profissional de Educação Física nas séries iniciais em relação aos dados dos alunos que foram acompanhados por pedagogos no mesmo período escolar. Assim, para este grupo de estudos, pode-se perceber que tanto professore de educação física quanto pedagogos que atuam nas instituições, parecem não estar preocupados com o desenvolvimento de atividades que aprimorem o equilíbrio e o tempo de reação nas aulas de educação física. Sendo nesse período que se deve propiciar uma ampla gama de oportunidades motoras, para que o aluno explore sua capacidade de movimentação, descubra novas expressões corporais, domine seu corpo em várias situações, experimente ações motoras com novos implementos e ritmos variados. O professor deverá procurar levar aos alunos, ao realizar ações motoras, a compreensão do seu significado e as suas formas de execução.

Um dos grandes problemas que se pode enumerar quanto às dificuldades que $o$ profissional de educação física tem para ministrar aulas nas séries iniciais, é a falta de propostas pedagógicas mais concretas, que justifiquem a existência e permanência da disciplina educação física no currículo escolar, e a sistematização dos conteúdos de

Pensar a Prática, Goiânia, v. 14, n. 2, p. 1-15, maio/ago. 2011 
forma organizada respeitando uma sequência pedagógica para as seriações já indicadas que pode contribuir para torná-la mais próxima da dinâmica da cultura escolar (KAWASHIMA; SOUZA; FERREIRA, 2009).

Almeida Jr. (2000) procurou analisar a situação da educação física no Ensino Fundamental (séries iniciais), a partir da observação e entrevista com professoras que atuam no referido período escolar. Os resultados indicaram que as intervenções destas professoras nas aulas são poucas, restringindo-se a entregar a bola, informar os alunos sobre o tempo restante das aulas, ou separar alguma discussão dos alunos.

O estudo citado acima se complementa ao analisar os dados encontrados por Silveira (1999), o qual identificou que a unidocência nas séries iniciais de escolarização, geralmente não atende à carga horária destinada para a educação física escolar (frequência e duração semanal), ainda coloca que os unidocentes enfrentam muitas dificuldades ao desenvolver as atividades inerentes a esta disciplina, principalmente pela falta de preparo (qualificação e respaldo teórico). O que faz com que os professores de sala de aula defendam, segundo o autor, a presença de um profissional qualificado de educação física para atender os alunos.

A partir da presença deste profissional qualificado pretende-se que crianças que se encontram no período escolar do $1^{\circ}$ ao $5^{\circ}$ ano, sejam submetidas nas aulas de educação física a atividades que desenvolvam habilidades motoras de base em qualidade e quantidades suficientes, proporcionando aos alunos a detenção de uma formação coordenativa que vai funcionar como um pressuposto para um aproveitamento máximo de um período mais favorável para aprendizagem de técnicas desportivas de base a partir dos anos seguintes. O desenvolvimento de capacidades físico-motoras e habilidades motoras básicas resultam da interação de fatores endógenos, determinados essencialmente pelo crescimento e maturação, e fatores exógenos, respeitando os estímulos provenientes do meio ambiente (CARVALHO, 1994).

Confirmando a constatação acima, Mattos e Neira (2000) em seu estudo relatam que a Educação Física não é privilegiada na maioria das escolas de Ensino Fundamental nas séries iniciais, o que pode ocasionar deficiências motoras, pois com 12 anos, idade em que a maioria das crianças sai deste período escolar, o padrão de movimento da criança estará praticamente definido, sendo quase impossível obter esquemas de ação para uma motricidade eficiente depois dessa idade. Com esta constatação fica evidente a importância de se efetivar a disciplina de Educação Física na escola nas primeiras séries do ensino fundamental, sendo responsabilidade do profissional desta área oportunizar aos alunos diferentes vivências lúdicas, visando ampliar o repertório motor dos alunos.

Quanto às capacidades elencadas, equilíbrio e tempo de reação, acredita-se que são de grande importância para o período de vida dos alunos sendo componentes motores que devem estar inclusos em qualquer planejamento curricular de Educação Física, seja qual for a abordagem metodológica utilizada pelo professor considerando que ambas fazem parte do cotidiano de qualquer indivíduo, servindo de base para outras atividades.

Apenas um estudo foi encontrado se preocupando em investigar estas duas capacidades ao mesmo tempo com crianças nesta faixa etária, Marmeleira e Abreu (2007) compararam o desenvolvimento da proficiência motora de crianças não-ciganas com o de crianças ciganas que frequentavam os primeiros anos de ensino básico na cidade de Lisboa em Portugal, utilizando o TBO 14, em que os resultados dos testes de

Pensar a Prática, Goiânia, v. 14, n. 2, p. 1-15, maio/ago. 2011 
equilíbrio estático e tempo de reação foram inferiores aos resultados do estudo aqui desenvolvido, já no teste de equilíbrio dinâmico o grupo de Portugal teve melhor desempenho em relação ao resultado do grupo aqui explorado.

Quanto ao tempo de reação estudos têm apontado (FOZARD et al.,1990; MACDOWD; BIRREN, 1990; CHAMBERLIN; MAGILL, 1989) para a importância do estímulo ao desenvolvimento de atividades físicas com a presença desta capacidade sendo esta de fundamental importância para situações do cotidiano como evitar quedas, interceptar objetos, desviar de obstáculos com o deslocamento em bicicleta, patins ou similares, e, também para futuras situações no esporte como interceptar bolas em jogo, realizar a cortada no voleibol, a saída na natação ou atletismo, entre outros.

Estudos referentes às atividades esportivas têm se detido em investigar o tempo de reação e equilíbrio. Em relação ao tempo de reação Pereira et al. (2009) investigaram a relação entre os desempenhos nas avaliações dos tempos de reação simples e de escolha com o desempenho motor do nado crawl com jovens em diferentes estágios de aprendizagem, no qual os resultados apontaram que o tempo de reação possui uma importância geral para o desempenho do nado, apresentando uma relevância maior nos grupos iniciante e avançado.

Vaghetti, Roesler e Andrade (2007) buscaram relacionar o desempenho do tempo de reação com o do surf. O tempo de reação foi utilizado como uma medida que representa o nível de coordenação neuromuscular, no qual os estímulos visuais, auditivos ou táteis são identificados por meio de diferentes processos do organismo. Com isso, verificou-se neste estudo que o tempo de reação simples, com estímulos auditivo e visual, apresentou grande importância para o desempenho motor no surf, havendo diferenças significativas entre o desempenho de tempo de reação comparando grupos de atletas profissionais, amadores e sujeitos apenas praticantes. Percebe-se que em relação aos dois estudos citados, quanto melhor o desempenho na habilidade motora, melhor o tempo de reação.

Em relação ao equilíbrio, Sá e Pereira (2003) verificaram a influência de um treinamento específico em crianças praticantes de judô, no qual também não encontraram diferenças significativas em relação ao pré e pós-testes. Deve-se levar em conta que nesse estudo foi realizado um treinamento de três vezes na semana com duração de 50 minutos, contabilizando 36 sessões, voltado para desenvolvimento do equilíbrio. Pelas médias do estudo, pode-se observar que o desempenho obtido a partir dos resultados do grupo foi um pouco melhor quando comparado com os resultados obtidos no estudo aqui relatado, o que se faz constatar a importância do desenvolvimento de um programa específico com o foco na habilidade básica que se pretende aprimorar, pois mesmo num tempo curto de treinamento foi possível constatar melhoras no desempenho.

Lemos et al. (2008) analisaram a influência do treinamento de futebol para a melhora do equilíbrio corporal em meninos de seis a nove anos de idade, no qual foram realizadas 12 sessões de treinamento do futebol, não sendo realizado nenhum tipo de treinamento voltado para o desenvolvimento do equilíbrio, neste estudo não foram evidenciadas melhoras em relação ao equilíbrio do grupo investigado, comparando com o estudo citado acima pode-se afirmar o quanto é importante o treinamento específico para o aprimoramento desta capacidade.

Pensar a Prática, Goiânia, v. 14, n. 2, p. 1-15, maio/ago. 2011 
10.5216/rpp.v14i2.11443

Lopes e Pereira (2004) verificaram se a natação exercia influencia na melhora do equilíbrio dinâmico e estático de crianças de 3 e 4 anos, dividindo estes em dois grupos o primeiro que realizava natação (grupo experimental) e o segundo não realizava nenhum tipo de atividade física (grupo controle). Após a realização do pré-teste o grupo experimental realizou a prática da natação durante 4 meses, sendo duas sessões semanais de 40 minutos. Após este período foi realizado um pós-teste que evidenciou melhoras significativas em todos os sujeitos do grupo experimental.

Assim, pode-se evidenciar a importância da prática de atividades físicas para a melhora das capacidades motoras e o quanto as experiências motoras fora da escola podem ter influenciado nos resultados obtidos, isso pode ser observado por meio da entrevista, a maioria dos alunos que não vivenciou a Educação Física na escola nas séries iniciais participam de escolinhas de esportes, natação ou dança, fato que contribuiu para uma melhora do desempenho motor, pois quanto maior o tempo de vivência motora, maior o nível de habilidade do sujeito (MAGILL, 2000). Já os alunos que tiveram acompanhamento do professor de educação física nas séries iniciais, em sua maioria não participam de atividades motoras fora da Educação Física escolar, sendo considerado o tempo de aula nas escolas muito escasso para que se possa contemplar todos os conteúdos propostos pela cultura corporal de movimento elencados nos Parâmetros Curriculares Nacionais.

Em relação a diferentes oportunidades de práticas e instrução, Cotrim et al. (2010) desenvolveram um estudo com crianças de 10 e 11 anos do ensino fundamental utilizando os subtestes locomotor e controle de objetos do TGMD-2, no qual as crianças com maiores oportunidades de prática e instrução obtiveram melhores resultados em relação ao grupo com menores oportunidades de prática e instrução, sugerindo que a prática estruturada e organizada de Educação Física nas séries iniciais é importante para o desenvolvimento de capacidades físico-motoras e habilidades básicas.

Afirmando a constatação do estudo acima Berleze, Haffner e Valentine (2007) além de evidenciarem que o desenvolvimento motor e de habilidades não depende somente da maturação motora da criança, evidenciam que é muito importante a criança frequentar espaços físicos que possibilitem a realização do brinquedo e que os ambientes escolar e, principalmente, familiar a que elas pertencem, e a estimulação a que estão sendo submetidas, são de fundamental importância para que se possa complementar este desenvolvimento motor pleno da criança.

Sendo assim, deve-se sempre exaltar a importância do componente curricular Educação Física estar presente no currículo escolar de todas as Instituições de Ensino a partir dos primeiros anos do ensino fundamental, pois este é essencial para que possa despertar na criança além do amplo desenvolvimento de um bom repertório motor, serve para que a criança utilize destes conhecimentos que vai obter, para que busque e vivencie fora da escola experiências motoras que complementem o que está sendo desenvolvido, sendo estes benéficos para o desenvolvimento de atividades futuras a que estes indivíduos irão experimentar.

\section{Conclusão}

Considerando a escola como o local adequado para difundir o gosto pelas atividades físicas, favorecendo o aprimoramento das capacidades físico-motoras $\mathrm{e}$ 
10.5216/rpp.v14i2.11443

habilidades motoras, o desenvolvimento deste trabalho possibilitou uma breve visão, talvez pouco profunda, de como a Educação Física nas escolas municipais situadas na cidade de Santa Maria está sendo desenvolvida nas séries iniciais do ensino fundamental.

O que pode ser notado é que não são todas as escolas que oferecem a Educação Física como um componente obrigatório de seus currículos nas séries iniciais, sendo contemplado apenas a partir do $5^{\circ}$ ano de ensino fundamental, em que o professor da classe, o Pedagogo, é responsável por ministrar aulas de educação física.

Finalizando, ressalta-se que ao verificar o nível de equilíbrio e o tempo de reação de escolares com e sem professor de educação física nas séries iniciais e identificar o cotidiano e vivências motoras dos grupos, não houve diferenças significativas na comparação dos grupos para os testes realizados, e ainda, que a maioria dos alunos que não vivenciaram aulas de educação física nas séries iniciais participam de escolinhas além das aulas de educação física escolar, assim como têm mais acesso a espaços para realização de brincadeiras e atividades físicas.

Com isso, pode-se concluir que tanto profissionais de educação física quanto pedagogos que atuam nestas instituições, não estão se preocupando com 0 desenvolvimento de atividades que aprimorem o equilíbrio e tempo de reação, entretanto, e felizmente pode-se perceber que as vivências de atividades fora da escola estão contribuindo para a aquisição de uma boa base motora, para o grupo investigado.

\section{Referências}

ALMEIDA Jr, O. A prática pedagógica das professoras de 1a. a 4a. séries nas aulas de educação física. SP: UNESP, 2000.

$\begin{array}{llrlrl}\text { ALVES, R.F.; TEIXEIRA C.S. Equilíbrio corporal de crianças praticantes } & \text { de } \\ \text { futebol. } & \text { Buenos } & \text { Aires, } & 2008 . & \text { Disponível } & \text { em: }\end{array}$ http://www.efdeportes.com/efd127/equilibrio-corporal-de-criancas-praticantes-de-futebol.htm $>$ Acesso em: 28/05/2010.

BETTI, M.; ZULLIANE, L.R. Educação Física escolar: uma proposta de diretrizes pedagógicas. Revista Mackenzie de Educação Física e Esporte, São Paulo, v. 1, n. 1, 2002.

Disponível

em:

http://www3.mackenzie.br/editora/index.php/remef/article/viewFile/1364/1067 >. Acesso em: 21/05/2010.

BERLEZE, A.; HAFFNER, L.S.B.; VALENTINE, N.C. Desempenho motor de crianças obesas: uma investigação do processo e produto de habilidades motoras fundamentais. Revista Brasileira de Cineantropometria, v. 9, n. 2, p. $134-144$, 2007.

BINOTTO, M.A. Atividade física e tempo de reação em mulheres idosas. 2007. Dissertação (Mestrado em Educação Física) - Universidade Federal de Santa Catarina, Santa Catarina, 2007.

Pensar a Prática, Goiânia, v. 14, n. 2, p. 1-15, maio/ago. 2011 
10.5216/rpp.v14i2.11443

BRUININKS, R. Bruininks-Oseretsky Test of Motor Proficiency: examiner's manual. Minnesota: American Guidance Service, 1978.

CARVAlHO, A.D.V. Desenvolvimento, Capacidades Motoras e Rendimento Motor: a Influência dos contextos rural e urbano. 1994. Dissertação (Mestrado em Motricidade Humana) - Faculdade de Motricidade Humana, Lisboa, 1994.

CHAMBERLIN, C.J.; MAGILL, R.A. Preparation and control of rapid, multisegmented responses in simple and choice environments. Res Q. Exercise Sport. 1989.

COTRIM, J.R.; LEMOS, A.G.; NÉRI JR, J.E.; BARELA, J.A. Desenvolvimento das habilidades motoras fundamentais em crianças com diferentes oportunidades de prática e instrução no ensino fundamental. Anais do V Congresso Brasileiro de Comportamento Motor. Brazilian Journal of Motor Behavior, v. 5, p. 40, 2010.

DARIDO, S.C.; RANGEL I.C. Educação física na escola. RJ: Editora Guanabara, 2005.

FOZARD, J.L.; VERCRUYSSEN, M.; REYNOLDS, S.L.; HANCOCK, P.A. Longitudinal analysis of age-related slowing: BLSA reaction time data. In: Proceedings of the Human Factors Society. p. 163-167), Santa Monica, CA: Human Factors Society, 1990.

JEBER, L.J. Plano de ensino em Educação Física escolar: um projeto político pedagógico em ação. In: Trilhas e partilhas: Educação Física na cultura escolar e nas práticas sociais. Belo Horizonte: Cultura, p. 113-143, 1997.

JOHNSON, B.L.; NELSON, J.K. Pratic Measurements for Evolution in Phisical Education. $4^{\text {a }}$ ed. Edina, MN. Brugess, 1986.

KAWASHIMA, L.B.; SOUZA, L.B.; FERREIRA, L.A. Sistematização de conteúdos da Educação Física para as séries iniciais. Revista Motriz, v.15, n. 2, p. 458-468, SP, 2009.

LEMOS, L.F.C.; ALVES, R.F.; TEIXEIRA, C.S; MOTA, C.B. Futebol de campo e o equilíbrio corporal de adolescentes. Revista Brasileira de Ciência e Movimento, v. 16, p. 1-19, 2008.

LOPES, M.G.O; PEREIRA, J.S. A influência da natação sobre o equilíbrio em crianças. Fitness \& Performance Journal, v.3, n.4, p.201-206, 2004.

MAGILL, R. Aprendizagem motora: conceitos e aplicações. SP: Editora Blucher, $2^{\mathrm{a}}$ edição, 2000. 
10.5216/rpp.v14i2.11443

MARMELEIRA, J.F.F.; ABREU, J.P. O desenvolvimento da proficiência motora em crianças ciganas e não-ciganas: um estudo comparativo. Revista Motricidade, v. 3, n. 1, Portugal, 2007.

MATTOS, M.G.; NEIRA, M.G. Educação Física na Adolescência: construindo o conhecimento na escola. SP: Phorte, 2000.

MCDOWD, J.M.; BIRREN, J.E. Agging and attentional processes. In: J. E. Birren \& K. W. Schaie. Handbook of the psycology of aging, $3^{\mathrm{a}}$ edição. NY: Academic Press, 1990.

MOCHIZUKI, L.; AMADIO, A.C . Análise da coordenação motora em tarefa de equilíbrio: sinergia do movimento. In: II Congresso Brasileiro de Comportamento Motor, 2004, Belo Horizonte. Anais do II Congresso Brasileiro de Comportamento Motor, 2004. v. 1.

PEREIRA, E.F.; TEIXEIRA, C.S.; VILLIS, J.M.C.; CORAZZA, S.T. Tempo de reação e desempenho motor do nado crawl em diferentes estágios de aprendizagem. Fisioterapia em movimento. Paraná, v. 22, n.4, 2009.

SÁ,V. W.; PEREIRA, J.S. Influência de um programa de treinamento físico específico no equilíbrio e coordenação motora em crianças iniciantes no judô. Revista Brasileira de Ciência e Movimento, Brasília v. 11 n. 1, 2003.

SANTOS S.; DANTAS L.; OLIVEIRA J.A. Desenvolvimento motor de crianças, de idosos e de pessoas com transtorno de coordenação. Revista Paulista de Educação Física. SP, 2004.

SCHMIDT, R.A.; WRISBERG, C.A. Aprendizagem e performance motora: uma abordagem da aprendizagem baseada no problema. Porto Alegre: Artmed, 2001, $2^{\text {a }}$ edição;

SCHMIDT, R.A.; WRISBERG, C.A. Aprendizagem e performance motora: uma abordagem da aprendizagem baseada no problema. Porto Alegre: Artmed, 2010, $4^{\text {a }}$ edição.

SILVEIRA, P.S. A legitimidade da educação física em Jataí- Goiás. Jataí, GO: 1999. Monografia (Licenciatura em Educação Física) - Campus Avançado de Jataí, Universidade Federal de Goiás, 1999.

SILVA, A.B.; FILHO, E.S.P. Implicações da ausência da Educação Física no $1^{\circ}$ e $2^{\circ}$ ciclo do ensino fundamental. 2004. Monografia (Especialização em Recreação) Faculdades Integradas Maria Thereza, Rio de Janeiro, 2004. 
10.5216/rpp.v14i2.11443

SOARES, C.L. Curso de Aperfeiçoamento para professores de Educação Física atuantes no $2^{\circ}$ grau. Curitiba, PR: Paraná - Secretaria do Estado da Educação, 1984 (Apostila).

SONZA, A.; MACHADO, D.B.; MOCHIZUKI, L. Equilíbrio estático de crianças em diferentes superfícies e posturas. In Anais eletrônicos, XI Congresso Brasileiro de Biomecânica. João Pessoa: UFP, 2005.

SPIRDUSO, W.W. Dimensões físicas do envelhecimento. Barueri - SP: Manole, 2005;

TANI, G.; MANOEL, E.J.; KOKUBUN, E.; PROENÇA, J. E. Educação física escolar: fundamentos de uma abordagem desenvolvimentista. São Paulo, 2005.

VAGO, T.M. Início e fim do século XX: maneiras de fazer educação física na escola. Cadernos Cedes. Corpo e educação. Campinas, Ano XIX, n.48. p. 30-51, 1999.

VAGHETTI, C.A.O; ROESLER, H.; ANDRADE, A. Tempo de reação simples auditivo e visual em surfistas com diferentes níveis de habilidade: comparação entre atletas profissionais, amadores e praticantes. Revista Brasileira de Medicina do Esporte. v. 13, n. 2, 2007.

\title{
REACTION TIME AND BALANCE OF SCHOOL WITH AND WITHOUT OF PHYSICAL EDUCATION TEACHER IN PRIMARY SCHOOL
}

\begin{abstract}
The aim of this study is to evaluate the balance level and reaction time of primary school children who have ever or not been overseen by a Physical Education teacher. In this regard, their motor experiences and daily lives also matter. To carry out the survey, seventy six students from the fifth grade of the primary school were sampled. The relevant variables were evaluated through two TBO 14 tests. To assess the students everyday lives and motor experiences, an interview was applied. Data were statistically handled through a T-test, at a 5\% significance level, according to which no statistically significant difference was found. The results coming out of the interviews showed that most of the students who had never gone through physical education use to practice physical activities outside school (60\%), which might have influenced the test outcomes.
\end{abstract}

Keywords: Physical Education. Balance. Reaction Time. Primary School.

\section{TIEMPO DE REACCIÓN Y EL EQUILIBRIO DE ESTUDIANTES CON Y SIN PROFESOR DE EDUCACIÓN FÍSICA EN LAS PRIMERAS SERIES}


Resumen: El objetivo del estudio fue determinar el nivel de equilibrio y el tiempo de reacción de los estudiantes con y sin profesor de educación física en las primeras series y para identificar lo cotidiano y las experiencias motrices de los grupos. Participaron del estudio 76 estudiantes en el quinto año de primaria. La evaluación de las variables se realizó mediante dos pruebas de 14 TBO, para evaluar lo cotidiano y las experiencias motrices de los estudiantes se utilizaron una entrevista. Los datos fueron analizados estadísticamente con la Prueba t, con un nivel de significancia del 5\%, donde no se ha encontrado diferencias estadísticamente significativas. En las entrevistas, los resultados revelaron que la mayoría de los estudiantes que no tuvieron la educación física participa en actividades físicas fuera de la escuela (60\%), lo que puede haber influido en los resultados de las pruebas.

Palabras clave: Educación Física. Equilibrio. Tiempo de Reacción. Primeras Series.

Endereço para correspondência:

luepalma@yahoo.com.br

Luciana Erina Palma

Universidade Federal de Santa Maria

Centro de Educação Física e Desportos,

Departamento de Métodos e Técnicas Desportivas

Campus Universitário, Km 09

Camobi

97105900 - Santa Maria, RS - Brasil

Pensar a Prática, Goiânia, v. 14, n. 2, p. 1-15, maio/ago. 2011 